NBER WORKING PAPER SERIES

THE EFFECT OF INCOME AND

COLLATERAL CONSTRAINTS ON

RESIDENTIAL MORTGAGE TERMINATIONS

Wayne Archer

David C. Ling

Gary A. McGill

Working Paper No. 5180

\author{
NATIONAL BUREAU OF ECONOMIC RESEARCH \\ 1050 Massachusetts Avenue \\ Cambridge, MA 02138 \\ July 1995
}

The authors acknowledge the helpful comments of Jim Follain, Patric Hendershott, Andy Naranjo, Tyler Yang, Peter Zorn, and participants at the National Bureau of Economic Research's 1994 Summer Institute Housing Workshop and Housing Market Dynamics Conference. This paper was prepared as part of the NBER Study on Housing Dynamics and was presented at the NBER Study Conference. Any opinions expressed are those of the authors and not those of the National Bureau of Economic Research.

() 1995 by Wayne Archer, David C. Ling and Gary A. McGill. All rights reserved. Short sections of text, not to exceed two paragraphs, may be quoted without explicit permission provided that full credit, including () notice, is given to the source. 


\title{
THE EFFECT OF INCOME AND \\ COLLATERAL CONSTRAINTS ON \\ RESIDENTIAL MORTGAGE TERMINATIONS
}

\begin{abstract}
The prepayment behavior of home mortgage borrowers has been widely observed to be inconsistent with behavior implied by classical option theory. A substantial literature has emerged examining the problem, focusing on the characteristics of the mortgage and on the historic path of interest rates in attempting to explain the anomaly. This paper offers contributions to the literature in three respects. First, it explores the influence of household level characteristics upon prepayment behavior, using both householder characteristics and collateral (house) value. Second, it empirically recognizes important interactions between the status of the prepayment option and the influence of income and collateral constraints upon prepayment behavior. Third, it uses a major source of data that has not previously been used in examining the prepayment anomaly: the American Housing Survey.

Among the findings are the following: when the household is either collateral constrained or income constrained, or the option is likely to be out of the money, the influence of the option value upon prepayment behavior is less by half. When the status of the option and the influence of potential household constraints are more appropriately recognized, these factors account for nearly all explanatory power otherwise attributable to household demographic characteristics.
\end{abstract}

Wayne Archer

Department of Finance and Real Estate

University of Florida

Gainesville, FL 32611
David C. Ling

Department of Finance and Real Estate University of Florida

Gainesville, FL 32611

Gary A. McGill

Fisher School of Accounting

University of Florida

Gainesville, FL 32611 


\section{Introduction}

An extensive literature exists on the 'options' imbedded in residential mortgages.' Endogenous or 'optimal' prepayment models 'predict' that borrowers with similar loans will react in a similar fashion to changes in market interest rates. But such behavior is not consistent with the empirical evidence: many borrowers fail to exercise well-into-the-money call options while others prepay when the call option is out-of-the-money. Clearly, interest rate influences on prepayment are conditioned upon non-interest rate factors.

The widespread appearance of 'suboptimal' prepayment behavior has led many academics and practitioners to displace the optimal-call model with fully exogenous, strictly empirical treatments of prepayment. The majority of empirical prepayment models are estimated using aggregate pool data that do not include information about underlying borrower characteristics or property values. $^{2}$ This is a significant limitation because it is the heterogeneity of borrowers within a pool that is widely assumed to account for differences in the responsiveness of borrowers to mortgage rate changes. For example, the age of the mortgage pool has been shown to be a statistically significant explanatory variable -- after the first twenty-four to thirty months, prepayment rates first accelerate then gradually slow or 'burnout'. However, the use of pool-level data does not allow the fundamental, or microeconomic, determinants of burnout to be assessed. ${ }^{3}$

' Hendershott and Van Order (1987) and Kau and Keenan (1994) review much of this literature

2 Empirical analyses of the prepayment experience of mortgage pools are reviewed by Dickinson and Heuson (1994).

${ }^{3}$ Another significant limitation of strictly empirical models results from the use of historical data: future call behavior in an empirical model is based on the historical sensitivity of prepayment rates to interest cost savings and other 
This paper attempts to identify household and property characteristics that influence the mortgage termination decision. Particular attention is paid to post-origination income and collateral constraints on refinancing activity. A borrower considering refinancing must first qualify for a new mortgage. Current qualification standards are such that a fall in household income or the value of the home used as collateral may make qualification for a new loan difficult. The idiosyncratic natures of both house price appreciation and changes in household income suggests that the incorporation of accurate post-origination borrower and property characteristics may improve our ability to explain cross-sectional variation in prepayment behavior.

This study uses microdata to examine empirically the prepayment behavior of 5,042 non-moving (non-defaulting) homeowners between 1985 and 1987. To capture more accurately property-specific variation in house price appreciation, an estimate of current property value is used to measure postorigination equity. The paper extends the prepayment literature by simultaneously considering the effects on termination of income and collateral constraints, as well as in-the-money call options. The major conclusion from these results is that the termination behavior of income or collateral constrained households differs markedly from unconstrained households. Further, these results suggest that household demographic characteristics -- such as age of household head and family size -- are only important to the extent that they are predictive of whether a household will be income or collateral constrained.

Several studies have used individual loan data to analyze mortgage terminations. These studies generally have found that borrower income and housing equity are significant determinants of mortgage terminations. However, the data employed in these studies are typically measured as of the mortgage

explanatory variables. Thus, there is the significant risk of structural change in prepayment behavior from past to future. 
origination date. Post-origination income and property values for individual observations are either proxied for by using their values at origination or estimated with aggregate adjustments. For example, Foster and Van Order (1985) and Quigley and Van Order (1990) estimated post-origination equity levels for each borrower by assuming house prices followed a stable Paretian distribution with a mean equal to the national average increase. Individual borrower income and property values in other studies are estimated using local or regional changes (Cunningham and Capone, 1990, and Capone and Cunningham, 1992). Caplin, Freeman, and Tracy (1993) simply divide their sample into locationally 'constrained' mortgages in states with 'weak' property markets and 'unconstrained' mortgages in states with 'relatively stable' property markets. ${ }^{4}$ The measurement of post-origination income and equity in these studies is hindered by data that are insufficient to capture the individuality of specific properties and borrowers Dickinson and Heuson (1993) include borrower income and house value at the time of refinancing, but their sample includes only households that refinance. ${ }^{5}$

The remainder of the paper is organized as follows. Section 2 reviews the relevant prepayment literature and section 3 presents the conceptual termination model. Section 4 describes the data and method used to test the model's predictions. Results and interpretations appear in section 5 and the last section offers some concluding remarks.

4 Over their 1990-1992 study period, they identified Connecticut, Florida, Massachusetts, New Jersey, New York, and Rhode Island as locationally constrained states.

' A sample containing only refinancers excludes both households that do not terminate their mortgages and households that terminate but do not refinance. 


\section{The relevant literature}

Optimal-call models are partial equilibrium models because they assume that mortgage termination decisions can be separated from the household's general optimization problem. More specifically, optimal-call models assume the desired amount of household mortgage debt is exogenously determined. Households maximize wealth in such a setting by adopting mortgage termination strategies that minimize the present value of their exogenously specified mortgage liability. Within the optimal-call model, prepayment behavior is strictly endogenous in that it is driven solely by past and expected future movements in interest rates. The borrower weighs the benefit of immediately refinancing (intrinsic value) against the benefit of waiting for a better opportunity (time value). Income and collateral constraints, portfolio considerations, and other borrower characteristics that may affect the termination decision are ignored. $^{6}$

The inability of the pure, frictionless, optimal-call model to explain mortgage terminations has generated numerous alternative treatments. One approach to explaining in-the-money non-calls is to include borrower transaction costs in optimal call models (e.g., Buser and Hendershott, 1984, Dunn and Spatt, 1986, Follain, Scott, and Yang, 1992, Giliberto and Ling, 1992). However, because these models assume borrower homogeneity, households are assumed to face identical exercise prices on their call options. As a result, these models do not address the varying lags, if not total non-responsiveness, of some borrowers to well-into-the-money call options.

A typical response has been to replace the optimal call model with more adaptable, fully exogenous, treatments of prepayment. The work of Schwartz and Torous $(1989,1992,1993)$ is representative. These strictly empirical

' Chinloy (1993) has developed a model in which prepayment and default functions are embedded in a theory of consumer behavior. 
valuation models rely on exogenously estimated hazard functions to account for both interest rate and non-interest rate driven prepayment behavior. This 'empirical' prepayment function is then integrated into a valuation framework to determine the mortgage cash flows in each (interest rate) state. Most empirically oriented termination research has had an extremely practical orientation -- if a variable or functional form improves the explanatory power of the model, it is used with little economic or logical justification. ${ }^{7}$ This is somewhat unsatisfying in that borrower prepayment behavior is passively accepted without rationally motivated explanations that can form the basis for further advancements. Rather than eliminating endogenous call, Archer and Ling (1993) and Stanton (1992) have developed rational models of mortgage prepayment that incorporate nonoptimal prepayment, yet retain endogenous call.

Any factor that creates resistance to the borrower who would prepay is, in effect, a transaction cost. Besides direct financial transaction costs, a wide range of other barriers may have this effect, including lack of creditworthiness, lack of comfort with financial affairs, opportunity cost of the time required for finding and arranging new financing, and perhaps other 'psychological' barriers. Archer and Ling (1993) and Stanton (1992) introduce heterogenous borrowers by assuming that transaction costs, expressed as a percentage of current loan balance, have a distribution across mortgages. They do not, however, identify specific borrower characteristics capable of explaining the apparently wide dispersion of borrower transaction costs around their mean value.

The following section presents a theoretical model of mortgage terminations. This model captures the effects of interest rate driven calls as well as the effects of household and property characteristics. In particular, the model, and the empirical estimation that follows, explicitly incorporates income and is king.

\footnotetext{
${ }^{7}$ In the competitive market for empirical prepayment models, 'R-Square'
} 
collateral constraints as additional impediments to termination. These impediments affect the distribution of transaction costs across borrowers and therefore the probability of mortgage termination.

\section{Conceptual framework}

\section{I A General Framework for Mortgage Terminations}

To interpret the analysis that follows, noting its relation to the larger context of all mortgage terminations is important. The probability of mortgage termination for all reasons at time $t, \lambda_{7 t}$, may be stated as:

$$
\lambda_{7 t}=\lambda_{D t}+\left(1-\lambda_{D}\right)\left[\lambda_{M t}+\left(1-\lambda_{M U}\right) \lambda_{P, N M H}\right]
$$

where:
$\lambda_{D t}$ is the probability of default at time $t$,
$\lambda_{M \prime}$ is the probability of moving (and terminating) at time $t$,
$\lambda_{P . N M t}$ is the probability of terminating (prepaying) the mortgage, conditional upon not moving. ${ }^{8}$

This study focuses entirely upon $\lambda_{P, M M r}$ Although the probability of default is ignored in what follows, it is important to note relationships between $\lambda_{P_{. N M}}$ and $\lambda_{M t}$ that become complications in broadening the analysis to include the probability of moving, $\lambda_{M r}$

The probability of moving, $\lambda_{M r}$ can be stated in general terms as:

$$
\lambda_{M t}=\lambda_{M t}\left(x_{t}, y_{t}, C_{\nu}\right)
$$

where: $\quad \boldsymbol{x}_{1}$ is a vector of household and property characteristics, $y_{r}$ is a vector of income opportunities related to potential moves.

and

$C_{t}$ is the value of the option to prepay an in-the-money call or to preserve the mortgage if interest rates have risen since origination.

${ }^{8}$ Note that this equation is consistent with a hierarchy of choices. The mortgagor can prepay and neither default nor move. Also, the mortgagor can move and not default. However, default implies both moving and 'prepaying', and moving implies prepaying. 
Note that if interest rates have risen, $C$, measures the extent to which the borrower is 'locked-in' to the current mortgage (Green and Shoven, 1986).

The value of the prepayment option at time $t$ can be stated in general terms as:

$$
C_{t}=C\left(\boldsymbol{x}_{n}, I R D_{r} \mathrm{P}, \lambda_{t+1}\right)
$$

where:

$\boldsymbol{x}$, is the same as above,

$I R D$, is the interest rate differential between the existing mortgage and new mortgages,

and

$P$ is a vector of parameters governing interest rate movements,

$\lambda_{t+1}$ is a vector of move probabilities from time $t+I$ to the end of the mortgage term.

The probability of prepayment without moving, $\lambda_{p . M M n}$, can be stated in general terms as:

$$
\lambda_{P . M M t}=\lambda_{P . M M M}\left(C_{p}, x_{t}\right)
$$

Equation (4) is the focus of this study. If the analysis were expanded to encompass moving behavior it would be confronted by the interdependency between the probability of moving in equation (2) and the value of the option in equation (3). Because $\lambda_{M}$ and $C_{f}$ are arguments in the equation for one another, neither variable is determined logically prior to the other. As a result, estimation of the value of the option and the probability of moving involves simultaneous equations. ${ }^{?}$

${ }^{9}$ This interdependency poses a difficulty in treating the various termination choices as either a nested or a multinomial alternative, as in Cunningham and Capone (1990) and Capone and Cunningham (1992). In a multinomial logit equation, for example, the odds ratio of moving versus simply

prepaying depends strictly on the ratio of two functions having the form $e^{\beta_{1}^{\prime} x}$, where the two exponents are each a linear expression in the exogenous vector $X$ But equations (2) and (3) imply that the probability of moving is an argument in the prepayment expression and call value is an argument in the move expression. Thus the $X$ vector, in substance. includes the probabilities being estimated. 
An important benefit of focusing only on $\lambda_{\mathrm{PNM}}$ is that the interdependency problem is 'upstream' in causality from the dependent variable. That is, $\lambda_{\mathrm{P} \text {.NMt }}$ does not appear as an argument in equation (2) or (3). Although the interdependency affects the value of $C_{t}$, the problem is strictly on the righthand side of the $\lambda_{P, N M t}$ equation.

To articulate the determinants of the conditional probability of prepayment, $\lambda_{P . N M l}$, we set out a simple model of the prepayment decision. We begin with an unconstrained borrower and then introduce the relevant constraints.

\subsection{Borrower behavior without constraints}

Assume the assets of owner-occupants at time $t$ consist of housing, $H_{t}$, and nonhousing, i.e., financial assets, $F_{r}$ Borrower financing choices are unconstrained by income or collateral value. The book value of the existing ("old") mortgage debt equals $B_{1}^{O}$, and $M_{1}^{O}$ represents the market value (cost) of the existing liability to the borrower. Let both $B_{i}^{O}$ and $M_{1}^{*}$ be values immediately after the scheduled payment at time t. Household wealth $\left(W_{t}\right)$ immediately after making the time $t$ mortgage payment is

$$
W_{t}=F_{t}+\left(H_{1}-M_{i}\right) \text {, }
$$

where $H_{t}-M_{t}^{\prime}$ represents the market value of housing equity under the existing financing.

In each period, the household observes the prevailing term structure of interest rates and makes a choice between (1) continuing the old mortgage as is for at least one additional period or (2) exercising the refinancing option and obtaining a new mortgage contract at current interest rates. Making the regularly scheduled payment "buys" the borrower the right again to consider both options in the next period. If the option is exercised, the new mortgage amount could be greater than, equal to, or less than $B^{\prime}$.

The option to refinance an amount equal to $B_{1}^{\prime \prime}$ is referred to as a 'pure' refinancing strategy because it does not simultaneously alter the book value of the household's capital structure. Rather, the decision is based solely on the 
desire to maximize household wealth -- for a given $F_{l}$ and $H_{t}$ by minimizing the cost of mortgage financing. For a pure refinancing to increase wealth more than the continuation strategy,

$$
M_{t}^{\prime}-M_{t}^{N}>T C_{1}
$$

where $M_{i}^{\prime}$ is the present value of the new mortgage liability and $T C$, equals the refinancing costs expected to be incurred by the borrower. Thus, the prepayment decision depends on the old mortgage rate and the new rate available at time $t$, the amount of refinanced debt $\left(B_{I}^{O}\right)$, and the level of transaction costs.

Optimal Loan-to-Value Ratios. The pure refinancing strategy abstracts from the borrower's general portfolio optimization problem in that the optimal amount of mortgage financing is implicitly assumed to equal $B_{t}^{\prime}$. However, households often rebalance their portfolios by borrowing, or paying down, an additional amount when refinancing. In fact, many households do not obtain a replacement mortgage when the existing mortgage is terminated. The wealth effect from a refinancing that simultaneously increases or decreases the household's use of mortgage debt has two aspects: the financial gain or loss from the pure refinancing and the gain from altering the mix of mortgage financing and own-equity financing. An implication of these alternatives is that the incentive to alter the household's capital structure may cause the original mortgage to be terminated even if the benefits from a pure refinancing do not exceed transaction costs. That is, it can be rational to prepay even if the option is not in the money, and this clearly depends on the differential between the borrowing rate and the investment return.

A general model of household capital structure would recognize mortgage terminations for the purpose of portfolio rebalancing as well as for simple cost savings. However, despite the relative importance of housing debt and equity in U.S. capital markets, a well-developed theory of the determinants 
of household loan-to-value ratios under uncertainty does not exist. ${ }^{10}$ In what follows, we assume the risk adjusted costs of mortgage debt and own-equity financing are equal, thereby ignoring the unresolved issue of optimal household capital structure. In substance, this assumption leads us to exclude the possibility of terminating for rebalancing purposes. The effect of this limitation is to add noise to our empirical estimations because we attempt to explain such terminations by a cost savings model.

The Conditional Probability of Prepaying. The values of the existing and new callable mortgages, $M_{\text {, and }}^{*} M_{1}^{N}$ consist of two components: (1) long positions in fixed-rate, amortizing, noncallable bonds having values $V N C^{\prime}$, and $V N C_{,}^{N}$ and (2) short positions in American-type call options on the noncallable bonds having values $C_{1}^{O}$ and $C_{t}^{N}$. Thus, $M_{t}^{O}-M_{t}^{N}$ from equation (6) can be rewritten as

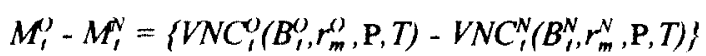

$$
\begin{aligned}
& \text { - }\left\{C_{t}^{O}\left(V N C_{t}^{O}, \lambda_{t+1}, \mathrm{P}, T\right)-C_{,}^{N}\left(V N C_{1}^{N}, \lambda_{t+i}, \mathrm{P}, T\right)\right\} \text {. }
\end{aligned}
$$

The specified functional form indicates that the noncallable bond values are a function of the book value of the underlying mortgages, $B_{1}^{()}$and $B_{1}^{N}$, the contract interest rates on the existing and new mortgages, $r_{m}^{o}$ and $r_{m}^{N}$, the vector $\mathbf{P}$ of parameters governing the interest rate process, and the remaining loan term, $T$.

The expanded form for the call options recognizes them as a complex function

${ }^{10}$ Brueckner (1994) and Jones (1993) develop theoretical models of the demand for mortgage debt by households. If the cost of equity financing is greater than the cost of mortgage debt -- and both costs are known with certainty -- both analyses predict that households will move to a corner solution -- i.e., they attempt to minimize the use of equity financing. However, the build-up of housing equity is a principal method of savings, and home buyers frequently make large downpayments. These observed interior solutions contradict the predictions of the certainty models. Brueckner shows that if cost of equity is random (risky), interior solutions are consistent with optimizing behavior. 
of the value of the underlying assets, the vector $\lambda_{1+1}$, of move probabilities from time $t+I$ forward, as well as $\mathrm{P}$ and $T$.

Using the expanded functional form for the call option values, the probability that the original mortgage will be terminated at time $t, \lambda_{\text {P.NM } t}$, is equal to the probability that

$$
\begin{gathered}
\left\{V N C_{1}^{\prime}\left(B_{1}^{\prime)}, r_{m}^{\prime)} \mathrm{P}, T\right)-V N C_{1}^{N}\left(B_{1}^{N}, r_{m}^{N}, \mathrm{P}, T\right)\right\}-\left\{C_{1}^{o}\left(V N C_{1}^{o}, \lambda_{1+1}, \mathrm{P}, T\right)\right. \\
\left.-C_{1}^{N}\left(V N C_{1}^{N}, \lambda_{1+l}, \mathrm{P}, T\right)\right\}>T C_{1 .} .
\end{gathered}
$$

The first term in equation (8) -- the difference between noncallable mortgage values -- represents the 'intrinsic' benefit of a current refinancing. Immediate exercise of the existing option results in the loss in value from a possible future exercise of the option. This lost option value is partially offset by the value of the call option embedded in the replacement mortgage. The difference in call option values must be subtracted from the intrinsic benefit to determine the adjusted benefit from refinancing an amount equal to $B_{i}$. The second term in equation (8) represents this deadweight loss. " The term on the right-hand side of the inequality -- transaction costs -- represents the amount, in dollars, that the benefits from a termination must exceed to increase wealth.

Let $I B_{t}=V N C_{1}^{\prime}-V N C_{1}^{N}$ represent the intrinsic benefit of a pure refinancing at time $t$ and let $D W L_{l}=C_{l}^{\prime}-C_{l}^{N}$ depict the deadweight loss in option value from an immediate exercise. The adjusted benefit from a refinancing is thus $I B_{t}-D W L_{r}$. Substitution of these terms into equation (8) shows that the probability of termination is equal to

$$
\lambda_{P^{\prime} N M}=P R O B\left(\left(I B_{1}-D W L_{1}\right)>T C_{1}\right\}
$$

The probability that a mortgage will be terminated can therefore be written as

"Empirical models of prepayment cannot capture changes in the time value of the option (i.e., the value of deferring exercise) subsequent to estimation. To see this, note that parameter estimates of these models incorporate only historical information. 
$\lambda_{P, N M t}=f\left\{I B_{t}\left(B_{l}^{\prime \prime}, B_{l}^{N}, r_{m}^{\prime)}, r_{m}^{N}, \mathrm{P}, T\right)\right.$

- $\left.D W L_{t}\left(B_{1}^{()}, B_{1}^{N}, r_{m}^{(3)}, r_{m}^{N}, \lambda_{t+1}, \mathrm{P}, T\right), T C_{t}\right\}$.

Equations (9) and (10) highlight the complexity of factors determining the conditional probability of refinancing. From equation (10), the decision to refinance depends in a complex way on the joint distribution of three variables: intrinsic benefit, deadweight loss, and transaction costs. However, these factors, as shown in equation (10), depend, in turn, on the joint distribution of additional underlying variables.

It is important to note that equation (10) approaches being a discontinuous function. If $T C_{1}$ is zero, then as $\left(I B_{1}-D W L_{1}\right)$ becomes negative -i.e., out-of-the-money -- the probability of termination, at some point, is likely to diminish abruptly. A positive value of $T C_{t}$ should merely shift upward the point at which this occurs. This issue has significant implications for empirical investigation of terminations, as noted below.

\subsection{Borrower behovior with constraints}

Equation (10) represents the probability of mortgage termination where the borrower is unconstrained with respect to income or collateral. It remains to consider the effect when the borrower becomes constrained.

The strategy of the borrower can be summarized as seeking to maximize wealth with respect to the two actions developed above: continuing the existing mortgage or exercising the prepayment option. However, the choice is subject to the following constraints:

$$
\begin{aligned}
& P_{t}^{N} \leq \mathbf{e} Y_{t} \\
& B_{t}^{N} \leq \delta H_{t}
\end{aligned}
$$

$\mathrm{Cl}$ constrains the mortgage payment $\left(P^{N}\right)$ to be less than or equal to a constant percentage, $\varrho$, of current income, $Y_{t}$. C2 constrains the mortgage amount $\left(B_{t}^{N}\right)$ to be less than or equal to a constant percentage, $\delta$, of the current house value.

The effect of $\mathrm{C} 1$ and $\mathrm{C} 2$ varies with the strategy considered. The first strategy, continuation of the existing debt (non-termination), is unaffected by the 
constraints, and thus is available in all cases. In contrast, the second strategy -refinancing an amount equal to $B_{f}^{()}$-- is subject to both constraints. This effect may be represented as a transformation of the probability of termination as follows:

$$
\lambda_{\mathrm{P} \mathrm{NMt}}=g\left\{f\left(I B_{l}(.), D W L_{l}(.), T C_{1}\right), C 1, C 2\right\} .
$$

In equation (11), any of three conditions imply a low probability of termination: a non-positive $\left(I B_{t}-D W L_{t}\right)$ so that the option is out-of-the-money or either of the two constraints binding. Thus, an empirical representation of equation (11) would need to reflect these quasi-discontinuous or shift factors.

A final point to note regarding equation (11) concerns fitting it to crosssectional data. The vector $\mathrm{P}$, and the variable $r_{m}^{N}$ that are in the IB and DWL functions are market-determined variables that will vary through time and must be accounted for in time-series analysis of (11). However, in a cross-sectional fitting of equation (11), these variables should be constant across the sample and will fall out of the analysis.

\section{Method}

\section{I Data}

The analysis uses data from the 1985 and 1987 American Housing Surveys (AHS) conducted by the U.S. Department of Commerce (U.S. Department of Commerce 1987, 1989). The AHS, conducted biennially, contains extensive micro-level data on household and property characteristics, including number, age, and marital status of occupants, income type and level, tenure status, original and current home values, home acquisition date, property tax payments, geographic location, etc. The AHS includes detailed mortgage information for owners, including the number and amount of mortgages, mortgage interest rates and payments, origination dates, and original and remaining loan terms. 
The AHS follows housing units rather than housing occupants. Accordingly, observations from the 1985 and 1987 AHS were matched on several criteria to ensure that the sample unit contained the same household in both years. The 27,490 usable owner households contained in the 1987 AHS were first matched with the 1985 owner households by unit control numbers. Next, observations were excluded that either (i) did not indicate that at least some of the same household members lived in the unit at the time of the 1985 survey,

or (ii) reported a move within the year prior to the 1987 survey. Finally, several other checks were conducted to compare household characteristics across the two sample years for stability or expected change (e.g., the age of the head and spouse should change by two years). The matching procedure yielded 18,279 non-moving owner households. Of these, 8,981 households did not have a mortgage in 1985 and 1,243 had other than a fixed-rate primary mortgage. Another 3,013 observations were excluded because of very small mortgage balances (less than 10 percent of house value) or lack of information necessary to determine whether the primary mortgage was terminated. The final sample used in the analysis contains 5,042 households.

4.2 Variables

Because this paper examines the variation across households in the response to in-the-money call options, it is important that the study period is one during which a significant number of households might consider the exercise of their call options. Figure 1 displays monthly mortgage rates from January of 1980 to December 1989. The AHS is conducted during the last four months of the survey year. Mortgage interest rates averaged 12.19 percent in September of 1985, the beginning of the $85-87$ window, after steadily declining from a record high of 18.45 percent in October of 1981. Rates continued to fall during the 8587 window, reaching a low of 9.04 percent in March of 1987. The 85-87 window was selected for use in this study because of the decline in interest rates both prior to and during this window. 
All variables used in the analysis are measured at the 1985 survey date except the dependent variable -- whether or not the household terminated its primary mortgage. A household is classified as terminating its primary mortgage or not based on a comparison of its 1985 and 1987 mortgage characteristics, including date obtained, type of mortgage, etc. The households that terminated their 1985 primary mortgage prior to the 1987 survey period constitute 33 percent of the sample. Table 1 provides descriptive statistics on the variables used in the analysis for the full sample and subgroups based on whether a termination occurred.

The book value of the primary mortgage is based on the household's actual mortgage interest rate and term. The market value of the primary mortgage is calculated as the present value of the remaining mortgage payments, discounted over the remaining loan period using the lowest Freddie Mac monthly commitment rate on 30 year fixed-rate mortgages between the 1985 and 1987 AHS survey period. ${ }^{12}$ Book loan-to-value ratio is the book value of total mortgage debt (primary plus any other mortgages) divided by the current fair market value of the residence. ${ }^{13}$ The intrinsic benefit from prepayment is the

12 The discount rate used to estimate market values of mortgages was $9.04 \%$ for the $1985-1987$ window. Rates during this window ranged from 10.71 to $9.04 \%$. Ideally, the valuation of mortgage liabilities at market would explicitly incorporate the borrower's embedded prepayment and default options which, in turn, depend on the household's privately held information regarding prepayment and default probabilities.

${ }^{13}$ Market value estimates by households have been shown to be accurate on average (e.g., Goodman and Ittner, 1992, Follain and Malpezzi, 1981, Kain and Quigley, 1972, and Robins and West, 1977). Goodman and Ittner found that the average U.S. owner overstates house value by six percent but that this error generally is uncorrelated with household characteristics. For our purposes, the household's estimate of current property value may be more important to the termination decision than 'true' market value. 
market value of the primary mortgage debt less the book value of the primary mortgage debt.

The annual payment-to-income ratio is calculated by assuming the current book value of the primary mortgage is refinanced as a fixed-rate 30 year mortgage at the prevailing rate. The denominator of this ratio is the household's total income including earned and investment income. Potential 'wasted' interest as a percentage of house value is used as a proxy for the mean weighted-average tax rate at which mortgage interest is deducted. ${ }^{14}$ Potential wasted interest represents the maximum amount of mortgage interest that will produce no tax savings due to the difference between the household's standard deduction and other itemized personal deductions, including property taxes. ${ }^{15}$ The sign of potential wasted interest is reversed because higher wasted interest represents a lower weighted average tax rate.

14 When testing the relationship between marginal tax rates and economic behavior, it is often difficult to distinguish between tax and income effects because marginal tax rates are usually a function of income. Thus, the advantage of using potential wasted interest as a proxy for the rate at which a household deducts its mortgage interest is that it varies independently of household income. The potential wasted interest amount is used in lieu of a household's actual wasted interest because potential wasted interest is exogenous to the household's leverage decision. For example, if a household has no mortgage debt, its actual wasted interest is zero. However, the household may have no mortgage debt because the deduction of the mortgage interest would have yielded little tax savings. The extent to which wasted mortgage interest deductions reduce the rate at which households deduct mortgage interest depends on the amount of wasted interest relative to the size of any mortgage actually chosen. However, to avoid an endogeneity problem for potential wasted interest as an explanatory variable, the amount of potential wasted interest is scaled by house value rather than actual mortgage size.

15 The AHS does not include information on non-housing personal expenses. Household level estimates of personal, non-housing, deductible expenses were added to the data set by imputation from the 1985 IRS Tax Model File. See Ling and McGill (1992) for a detailed discussion of wasted interest deductions and the use of IRS data to enhance the AHS data base. 
A household's mortgage prepayment option is considered 'in-the-money' if the ratio of the market value to the book value of the existing first mortgage exceeds one. Fifty percent of the sample has in-the-money options. A household is considered liquidity constrained with respect to mortgage borrowing if the annual payment-to-income ratio on a new mortgage exceeds 0.28 and collateral constrained if the current book loan-to-value ratio equals or exceeds 0.9 . In the sample, 9.5 percent of the households are liquidity constrained and 5.7 percent are collateral constrained. A combination variable, PLAYER, measures whether the household's mortgage option is 'in the money' and the household is neither liquidity nor collateral constrained. In the sample, 40.5 percent of the households are PLAYERs.

\subsection{Logistic regression model}

This section presents the empirical model used to estimate the effects suggested by the conceptual model summarized in equation (II). After specifying the logistic regression model, each of the variables is mapped back to the conceptual model and the expected direction of each effect is specified.

A logistic regression model is estimated where

$$
T E R M_{i}=\boldsymbol{b}^{\prime} \boldsymbol{x}_{i}+\mu_{i}
$$

$T E R M_{i}$ is a binary variable indicating whether household $i$ has terminated its primary mortgage by $1987 . \boldsymbol{b}^{\prime}$ is a row vector of coefficients, $\boldsymbol{x}_{i}$ is a vector of variables that explains the household's decision to terminate a mortgage, and $\mu_{i}$ is the random error term. The vector $\boldsymbol{x}_{i}$ contains characteristics of the household, property, and mortgage including: option value (OPTION), book loan-to-value ratio (LTVR), prospective payment-to-income ratio (PAYINC), potential wasted interest as a proxy for the marginal rate at which mortgage interest is deducted (TAX), total income (INC), age of household head (AGE), a dummy variable indicating whether the head attended two or more years of college (COLLEGE), a dummy variable indicating whether the income is from two wage earners (JOINTINC), a dummy variable indicating whether the property is located in a 
rural area (RURAL), the size of the family including spouses (FAMSIZE), whether the household is a first-time owner (FIRSTTIME) and the number of years at the current residence (HOWLONG).

In the empirical model, OPTION is set equal to the intrinsic benefit of refinancing, which is the market value less the book value of the primary mortgage debt. Although the intrinsic benefit overstates the value of the prepayment option because it is not reduced by the deadweight loss, as in equation (8), this is of consequence in a strictly cross-sectional study of prepayment behavior only if every household's deadweight loss is not identical. Under the usual assumption that interest rate expectations are homogeneous across households, cross-sectional variation in the deadweight loss is a function only of variation in 'old' mortgage coupon rates -- which we capture -- and household move probabilities. We at least partially control for differences in expected mobility with proxy variables, including HOWLONG, AGE, FAMSIZE, and FIRSTTIME. Thus, the empirical model is likely to capture the cross-sectional variation in the value of the prepayment option in our specification.

Transaction costs, $T C_{1}$ in the conceptual model, are captured by LTVR, representing a collateral constraint, PAYINC, representing a liquidity constraint, and INC, JOINTINC, TAX, AGE, COLLEGE, RURAL, FAMSIZE, FIRSTTIME, and HOWLONG, controlling for the heterogenous nature of borrowers. Because higher current loan-to-value ratios indicate greater collateral constraints, LTVR is expected to have a negative effect on the probability of termination. PAYINC should have a negative effect on termination because larger values of PAYINC represent a reduced ability to qualify for a new mortgage. Giliberto and Thibodeau (1989) and Dickinson and Heuson (1993) find that income has a positive effect on termination. However, the direction of the INC effect in our specification is unclear because INC captures the influence of total household income after controlling for whether the household income 
could support a new mortgage (PAYINC). Consequently, INC could proxy for features such as the financial sophistication of the household or the cost of nonpecuniary transaction costs such as the opportunity cost of time involved to exercise the call option. Similarly, JOINTINC is related to total income and its influence on liquidity constraints because two wage earners within a household might improve credit worthiness.

TAX, or the proxy for the weighted-average cost at which the household deducts mortgage interest, should be negatively related to the probability of termination because higher levels of TAX represent a lower after-tax cost of mortgage debt. Quigley (1987) found that the probability of termination is negatively related to the age of the household head and positively related to family size. If AGE or FAMSIZE have an effect it should be as a proxy for life cycle differences across households. COLLEGE and RURAL may proxy for characteristics such as financial sophistication, aversion to change, etc. and, if so, COLLEGE should be positively related to termination probability (Quigley 1987) with the influence of RURAL indeterminate. HOWLONG should be positively related to termination to the extent that this variable captures the immobility of the household; households with greater years at the current residence could be less mobile, and thus derive greater benefit from refinancing. The empirical model does not include proxies for $\boldsymbol{P}$ or $r_{m}^{N}$ since these factors do not vary crosssectionally.

As illustrated by equation (11), the effect of each explanatory variable is likely highly dependent on whether the household has an 'in-the-money' option, or is liquidity or collateral constrained. To test equation (11), the empirical model is estimated in two ways. First, the constraints of equation (11) are ignored and the empirical model is estimated as a non-interaction model (full sample with no partition for constraints). Next, to capture these quasidiscontinuous or shift factors, the model is estimated as a fully interactive model with a dummy variable -- PLAYER -- in order to examine the incremental 
intercept and slope effects of the household being a 'player' or not. Incorporation of this shift effect should remove or reduce the influence of the other explanatory variables. These two estimations are provided in Table 2.

\section{Empirical results}

Table 2 contains logistic regressions, with expected signs, parameter estimates, $p$-values of the associated Wald Chi-Square statistics, and measures of goodness-of-fit, including two classification rates. Model (I) is the OPTION only model. Model (2) is the non-interaction model, which ignores the potential discontinuous nature of the termination decision. Model (3) is the full interaction model with the dummy variable for 'player' interacted with all variables in order to examine the incremental intercept and slope effects of the household being a 'player' or not. The -2 Log Likelihood statistics are significant for all three models, indicating that the independent variables provide explanatory power, and the classification rates are superior to a naive model based on every household being classified as a non-terminator. ${ }^{16}$

\section{I Non-interaction model}

For comparison purposes a model is estimated with OPTION only and, as expected, OPTION is positive and significant. In Model (2), the noninteraction model, most of the explanatory variables are significant in the expected direction, where one is specified. OPTION is positive and strongly

16 The first classification rate in the table is a within-sample classification in which an observation is classified as an event or non-event based on the predicted probability from the logistic regression and then compared to its actual event status. The second classification rate is a paired-rank correlation (the ' $c$ ' statistic) in which all possible pairs of observations with different responses are compared and said to be concordant (discordant) if the observation with the higher response has a higher (lower) predicted probability than the lower level response. The latter measure uses the entire distribution of probabilities and is closest to a goodness-of-fit test. 
significant and LTVR is negative and significant, indicating that larger option values and increased collateral constraints have a direct effect on termination probability. PAYINC is not significant, indicating no income constraint effect. TAX is negative and significant as expected; the probability of termination decreases as TAX increases because higher levels of TAX represent lower aftertax costs of mortgage debt. The other household characteristics are all significant, except AGE and FIRSTTIME, and thus increase the explanatory power of the model compared with a model with mortgage and option characteristics only.

\subsection{Interaction model}

Model (3), the interaction model, includes a dummy variable for 'player', a measure designed to capture the quasi-discontinuous factors included in the constraints of equation (11). Households are 'players' when their options are in the money and they are neither liquidity nor collateral constrained. There is a significant upward shift in the intercept when households are PLAYERs; PLAYERs are more likely to terminate their mortgage, all else equal. As expected, the effects of OPTION and LTVR are significant in the expected direction for PLAYERs and demonstrate a significantly lesser influence on nonPLAYERs. PAYINC, non-significant in the non-interaction model, becomes significant and negative for PLAYERs. As the prospective payment burden increases, the more likely are households to find loan qualification difficult.

However, the PAYINC effect essentially disappears for non-PLAYERs; if the household cannot qualify for a new mortgage, the extent to which the household fails to meet underwriting standards is relatively unimportant.

TAX is significant and positive and has the same effect as in the noninteraction model; the influence of TAX on non-PLAYERs is no different than the PLAYER group. Most of the household demographic characteristics are no longer significant. INC is negative and significant, with increases in INC reducing the probability of termination for the PLAYER group. Recall that the 
INC effect is incremental to the PAYINC effect. HOWLONG is significantly and positively related to termination. The household characteristics do not have any different influence for the non-PLAYER group except for INC and FAMSIZE. The effect of INC is smaller for the non-PLAYER group, and FAMSIZE becomes more negative for the non-PLAYER group.

The major conclusion from these results is that the termination behavior of households that are income or collateral constrained differs markedly from unconstrained households. ${ }^{17}$ Further, these results suggest that household demographic characteristics -- such as family size and education level -- are only important to the extent that they are predictive of whether a household will be income or collateral constrained. Once the quasi-discontinuous natures of these constraints are explicitly incorporated by use of the shift variable PLAYER, the incremental explanatory power of the demographic variables is marginal. ${ }^{18}$

The sensitivity of the results to our specification of liquidity constrained was examined in two ways. First, the measure of liquidity constrained used in the PLAYER classification was based on $0.35,0.40$, and 0.50 , instead of the 0.28 cutoff for PAYINC. The interpretation of the logistic regression results remained the same under all three alternatives. Second, the payment-to-income ratio in the PLAYER classification was estimated using the actual mortgage payment rather than the prospective mortgage payment. Again, the interpretation of the logistic regression results did not change from the original variable specification.

17 Linneman and Wachter (1989) find that borrower constraints adversely affect home ownership propensities.

${ }^{18}$ These results are not sensitive to our specification of the shift factor as PLAYER versus non-PLAYER, instead of separate estimations for constrained groups with a dummy variable for whether the household is 'in-themoney'. 


\subsection{Simulation Results}

Simulation results based on the full interaction model are presented in Table 2 (last two columns) and Table 3 in order to clarify the effect of household characteristics and prepayment constraints on the probability of termination. The simulation results in Table 2 are derived in two ways. For classification characteristics (dummy variables), the simulation parameter represents the incremental effect on the probability of termination of a household possessing that characteristic. For continuous characteristics, the simulation parameter represents the change in probability of termination given a one standard deviation change in the explanatory variable. For example, a one standard deviation increase in household income decreases the probability of termination by 8.1 percent for PLAYERS. However, income changes have virtually no effect on the termination probabilities of non-PLAYERS. All the simulation effects in Table 2 are constructed using means and standard deviations for the entire sample population, as reported in Table 1.

The importance of the option value stands out in two respects. First, its influence is twice as large for PLAYERs as for non-PLAYERs (0.190 versus 0.097). Second, the influence of the option value for PLAYERs is large relative to household characteristics, exceeding the influence of total income by a factor of two, and exceeding the effect of most other characteristics by much more. ${ }^{19}$

The importance of the prospective payment-to-income ratio also is reinforced by the simulation results. Even among PLAYERs -- all having the

${ }^{19}$ It is arguable that the influence of option value relative to household characteristics is understated in Table 2 because the variation in option value captured in any cross-sectional study understates the potential variation in option value over time. Referring to Figure 1, for example, the full range of option values arguably would include those based on high interest rate loans from the early 1980s that were refinanced prior to our sample period. 
acceptable payment-to-income ratio -- the effect of an increase in PAYINC on the probability of termination is the single largest variable effect

The importance of being a PLAYER is suggested by the difference in the intercept terms; being a PLAYER increases the probability of termination by 43.7 percentage points (-0.218 for a non-PLAYER versus 0.219 for a PLAYER). However, the intercept difference between PLAYERS and non-PLAYERS is a partial effect; it does not capture the interaction between PLAYER and other explanatory variables.

The overall effect of income and collateral constraints on the exercise of in-the-money prepayment options is directly examined in Table 3 , which reports probabilities of termination for the set of households classified as PLAYERs (in-the-money and unconstrained). The table values are predicted mortgage termination probabilities using the PLAYER coefficients from the logistic regression, evaluated at mean values for the PLAYER subset of sample except where a constraint is imposed (as noted). Each panel represents a different state of the prepayment option: panel $A$, in-the-money (the 'natural' case for PLAYERs); panel B, at-the-money; and panel C, deep out-of-the money. The two columns report probabilities of termination under two levels of simulated constraint: marginally constrained (column I) and deeply constrained (column 2).

These tests dramatize the significance of both the option value and the constraints. For the 'natural' case of PLAYERs (row 1 of Panel A) the probability of termination is 0.386 . However, raising the loan-to-value ratio (LTVR) to the threshold level of 0.9 (row 2 , column 1 ) reduces the probability of termination by nearly 40 percent, to a value of 0.236 . Raising LTVR to the mean of the constrained population (row 2, column 2) causes a drop of 55 percent to 0.170 . Further, raising the income constraint (PAYINC) to its threshold value (row 3 , column 1) causes the probability of termination to drop by 55 percent to 0.175 , and raising PAYINC to the mean of the constrained group (row 3, column 2) 
causes probability of termination to fall by 92 percent to 0.003 . Setting both constrained variables at their threshold levels (row 4 , column 1) causes the probability of termination to fall by 75 percent to 0.095 , while setting both constraint variables at the deeply constrained level (row 4, column 2) causes the probability of termination to approach zero.

The influence of the option value is affirmed by the differences among the three panels. When OPTION is reduced to being at-the-money (panel B), but without imposing constraints, the probability of termination falls by nearly 50 percent, from 0.386 to 0.197 . Imposing both threshold constraints reduces the probability of termination by almost 90 percent to 0.039 . The imposition of deeper constraints reduces it near to zero. Reducing OPTION still further to a deeply out-of-the-money state (panel $\mathrm{C}$ ), without constraints, lowers the probability of termination by more than 55 percent to 0.166 . Imposing any constraints reduces the probability of termination near to zero.

\section{Conclusion}

This paper attempts to identify household and property characteristics that influence the mortgage termination decision. Particular attention is paid to post-origination income and collateral constraints on refinancing activity. A borrower considering refinancing must first qualify for a new mortgage. Current qualification standards are such that a fall in household income or the value of the home used as collateral may make qualification for a new loan difficult. In addition, the responsiveness of a borrower to these and other factors will depend on whether the household's option is in-the-money. In order to capture these quasi-discontinuous effects, the logistic regression model is estimated with a measure of whether the household is a potential 'player', that is whether the household's mortgage option is 'in the money' and the household is neither liquidity nor collateral constrained. 
Using microdata, we empirically examine the mortgage prepayment behavior of 5,042 non-moving (non-defaulting) households between 1985 and 1987. The major conclusion from this analysis is that the termination behavior of households that are income or collateral constrained differs markedly from unconstrained households. In the non-interaction model estimation, most of the explanatory variables are significant in the expected direction. In particular, the household characteristic variables provide incremental explanatory power compared with a model with option and mortgage characteristics only. However, after introduction of the shift factor, PLAYER, in the interaction model, many of the household characteristic variables have little or no relationship with the termination decision. Further, the effects of the option and constraint variables for the PLAYER group differ significantly from those of the non-PLAYER group. These results suggest that household demographic characteristics are only important to the extent that they are predictive of whether a household will be income or collateral constrained. 
References

Archer, W.R. and D.C. Ling, 1993, Pricing mortgage-backed securities: Integrating optimal call and empirical models of prepayment, Journal of the American Real Estate and Urban Economics Association 21, 373404.

Brueckner, J.K., 1994, The Demand for mortgage debt: Some basic results, Working Paper, University of Illinois.

Buser, S.A. and P.H. Hendershott, 1984, Pricing default-free mortgages, Housing Finance Review 3, 405-429.

Capone, C.A. and D.F. Cunningham, 1992, Estimating the marginal contribution of adjustable-rate mortgage selection to termination probabilities in a nested model, Journal of Real Estate Finance and Economics 5, 333356.

Caplin, A., C. Freeman, and J. Tracy, 1993, Collateral damage: How refinancing constraints exacerbate regional recessions, National Bureau of Economic Research, Working Paper No. 4531, (November).

Chinloy, P., 1993, Elective mortgages prepayment: Termination and curtailment, Journal of the American Real Estate and Urban Economics Association 21, 313-332.

Cunningham, D.F. and C.A. Capone, 1990, The relative termination experience of adjustable to fixed-rate mortgages, Journal of Finance XLV, No. 5 , $1687-1703$.

Dickinson, A. and A.J. Heuson, 1994, Mortgage prepayments: Past and present, Journal of Real Estate Literature 2, 11-33.

Dickinson, A. and A.J. Heuson, 1993, Explaining refinancing decisions using microdata, Journal of the American Real Estate and Urban Economics Association 21, 293-311.

Dunn, K.B. and C.S. Spatt, 1986, The effect of refinancing costs and market imperfections on the optimal call strategy and the pricing of debt contracts, Working Paper, Carnegie-Mellon University (March).

Follain, J.R. and S. Malpezzi, 1981, Are occupants accurate appraisers? Review of Public Data Use 9, 47-55. 
Follain J.R., O. Scott, and T.L.T. Yang, 1992, Microfoundations of a mortgage prepayment function, Journal of Real Estate, Finance, and Economics $5,197-217$.

Foster, C. and R. Van Order, 1985, FHA terminations: A prelude to rational mortgage pricing, Journal of the American Real Estate and Urban Economics Association 13, 371-391.

Giliberto, S.M. and D.C. Ling, 1992, An empirical investigation of the contingent-claims approach to pricing residential mortgage debt, Journal of the American Real Estate and Urban Economics Association 20, 393-426.

Giliberto, S.M. and T.G. Thibodeau, 1989, Modeling conventional mortgage refinancings, Journal of Real Estate Finance and Economics 2, 285299.

Goodman, J.L. and J.B. Ittner, 1992, The accuracy of homeowners' estimates of house value, Journal of Housing Economics 2, 339-357.

Green, J. and J. Shoven, 1986, The effects of interest rates on mortgage prepayments, Journal of Money, Credit and Banking 18, 41-59.

Hendershott, P.H. and R. Van Order, 1987, Pricing mortgages: An interpretation of the models and the results, Journal of Financial Services Research 1, 19-55.

Jones, L.D., 1993, The Demand for home mortgage debt, Journal of Urban Economics 33, 10-28.

Kain, J.F. and J.M. Quigley, 1972, Note on owner's estimate of housing value, Journal of the American Statistical Association 67, 803-806.

Kau, J.B. and D.C. Keenan, 1994, An overview of the option-theoretic pricing of mortgages, Journal of Housing Research, forthcoming.

Ling, D.C. and G.A. McGill, 1992, Measuring the size and distributional effects of homeowner tax preferences, Journal of Housing Research 3, 273303.

Linneman, P. and S. Wachter, 1989, The impacts of borrowing constraints on homeownership, Journal of the American Real Estate and Urban Economics 17, 389-390. 
Quigley, J. M., 1987, Interest rate variations, mortgage prepayments and household mobility, Review of Economics and Statistics 69, 636-643.

Quigley, J.M. and R. Van Order, 1990, Efficiency in the mortgage market: The borrower's perspective, Journal of the American Real Estate and Urban Economics Association 18, 237-252.

Robins, P.K. and R.W. West, 1977, Measurement error in the estimation of home value, Journal of the American Statistical Association 72, 290-294.

Schwartz, E.S. and W.N. Torous, 1989, Prepayment and the valuation of mortgage-backed securities, Journal of Finance 44, 375-392.

Schwartz, E.S. and W.N. Torous, 1992, Prepayment, default, and the valuation of mortgage pass-through securities, Journal of Business 65, 221-239.

Schwartz, E.S. and W.N. Torous, 1993, Mortgage prepayment and default decisions: A poisson regression approach, Journal of the American Real Estate and Urban Economics Association 21, 431-449.

Stanton, R. 1992, Rational prepayment and the valuation of mortgage-backed securities, Working Paper, University of California--Berkeley.

U.S. Department of Commerce, Bureau of the Census, 1987, American Housing Survey 1985, (Computer File) Washington, D.C.

U.S. Department of Commerce, Bureau of the Census, 1989, American Housing Survey 1987, (Computer File) Washington, D.C. 


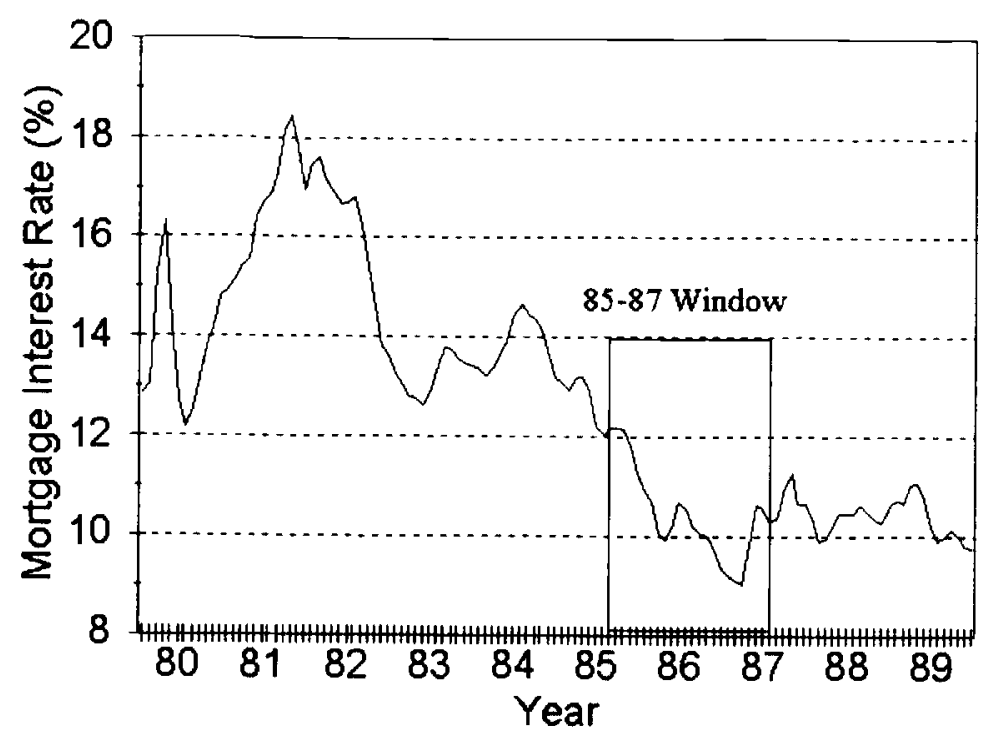

Fig. 1. Residential Mortgage Interest Rates: 1980-1989. ${ }^{\mathrm{a}}$

* Source is Freddie Mac's monthly commitment rate on 30 year fixed-rate residential mortgages. 
Table 1

1985 Descriptive Statistics: Non-Mover Home Owners With Primary Mortgage Sorted By Whether Primary Mortgage Terminated by $1987^{2}$

\begin{tabular}{|c|c|c|c|c|}
\hline & & $\begin{array}{l}\text { All Non- } \\
\text { Movers }\end{array}$ & $\begin{array}{c}\text { Non- } \\
\text { Terminators }\end{array}$ & Terminators \\
\hline Number of Sample Observations / Percent of Total & & $5,042 / 100 \%$ & $3,377 / 67 \%$ & $1,665 / 33 \%$ \\
\hline Options in-the-Money & $\%$ & 50 & 45 & 59.5 \\
\hline Liquidity Constrained & $\%$ & 9.5 & 9.1 & 10.2 \\
\hline Collateral Constrained $^{\lrcorner}$ & $\%$ & 5.7 & 6 & 5.2 \\
\hline $\begin{array}{l}\text { PLAYER } \\
\text { (option in the money and neither liquidity or collate } \\
\text { constrained) }\end{array}$ & $\%$ & 40.5 & 36 & 49.6 \\
\hline Current Fair Market Value of Residence ( $\$ 000^{\prime}$ s) & $\begin{array}{r}\text { Median } \\
\text { Mean } \\
\text { S.D. }\end{array}$ & $\begin{array}{r}70.0 \\
77.4 \\
(42.5)\end{array}$ & $\begin{array}{r}70.0 \\
79.2 \\
(41.6)\end{array}$ & $\begin{array}{r}65.0 \\
73.8 \\
(44.1)\end{array}$ \\
\hline Book Value of First Mortgage ( $\left.\$ 000^{\prime} \mathrm{s}\right)$ & $\begin{array}{l}\text { Median } \\
\text { Mean } \\
\text { S.D }\end{array}$ & $\begin{array}{r}25.0 \\
29.7 \\
(22.7)\end{array}$ & $\begin{array}{r}26.4 \\
30.4 \\
(21.0)\end{array}$ & $\begin{array}{r}20.4 \\
28.1 \\
(256)\end{array}$ \\
\hline Market Value of First Mortgage $\left(\$ 000^{\prime} \mathrm{s}\right)^{t}$ & $\begin{array}{c}\text { Median } \\
\text { Mean } \\
\text { S.D }\end{array}$ & $\begin{array}{r}25.1 \\
32.6 \\
(28.0)\end{array}$ & $\begin{array}{r}26.3 \\
32.5 \\
(25.3)\end{array}$ & $\begin{array}{r}20.9 \\
32.9 \\
(32.9)\end{array}$ \\
\hline
\end{tabular}


Table 1 (Continued)

\begin{tabular}{|c|c|c|c|c|}
\hline & & $\begin{array}{l}\text { All Non- } \\
\text { Movers }\end{array}$ & $\begin{array}{l}\text { Non- } \\
\text { Terminators }\end{array}$ & Terminators \\
\hline $\begin{array}{l}\text { Book Loan-to-Value Ratio } \\
\text { (total mortgage debt } \div \text { current residence fair market value) }\end{array}$ & $\begin{array}{r}\text { Median } \\
\text { Mean } \\
\text { S.D. }\end{array}$ & $\begin{array}{r}41.9 \\
44.7 \\
(27.6)\end{array}$ & $\begin{array}{r}42.5 \\
45.6 \\
(26.8)\end{array}$ & $\begin{array}{r}40.8 \\
42.9 \\
(29.0)\end{array}$ \\
\hline $\begin{array}{l}\text { Intrinsic Benefit from Ptepayment (\$) } \\
\text { (market value of first mortgage debt less book value of first } \\
\text { mortgage debt) }\end{array}$ & $\begin{array}{r}\text { Median } \\
\text { Mean } \\
\text { S.D. }\end{array}$ & $\begin{array}{r}-3.1 \\
2.955 \\
(7,307.3)\end{array}$ & $\begin{array}{r}-114.8 \\
2.025 \\
(6,207.9)\end{array}$ & $\begin{array}{r}546.8 \\
4.841 \\
(8,846.3)\end{array}$ \\
\hline $\begin{array}{l}\text { Annual Payment-to-Income Ratio } \\
\text { (as if current balance of first mortgage debt is refinanced as a } \\
\text { tixed-rate thirty year mortgage at market rate) }\end{array}$ & $\begin{array}{r}\text { Median } \\
\text { Mean } \\
\text { S.D. }\end{array}$ & $\begin{array}{r}10.6 \\
18.4 \\
(123.8)\end{array}$ & $\begin{array}{r}10.8 \\
16.3 \\
(31.2)\end{array}$ & $\begin{array}{r}10.1 \\
22.5 \\
(210.8)\end{array}$ \\
\hline Total Income ( $\$ 000$ 's) & $\begin{array}{r}\text { Median } \\
\text { Mean } \\
\text { S.D. }\end{array}$ & $\begin{array}{r}32.2 \\
35.5 \\
(21.6)\end{array}$ & $\begin{array}{r}33.0 \\
36.4 \\
(21.6)\end{array}$ & $\begin{array}{r}31.0 \\
33.8 \\
(21.6)\end{array}$ \\
\hline $\begin{array}{l}\text { Potential Wasted Interest as \% of Residence Fair Market } \\
\text { Value }^{:}\end{array}$ & $\begin{array}{c}\text { Median } \\
\text { Mean } \\
\text { S.D. }\end{array}$ & $\begin{array}{r}0.0 \\
-1.6 \\
(4.5)\end{array}$ & $\begin{array}{r}0.0 \\
-1.2 \\
(2.7)\end{array}$ & $\begin{array}{r}0.0 \\
-2.4 \\
(6.8)\end{array}$ \\
\hline Age of Household Head & $\begin{array}{c}\text { Median } \\
\text { Mean } \\
\text { S.D. }\end{array}$ & $\begin{array}{r}42 \\
44 \\
(12)\end{array}$ & $\begin{array}{r}42 \\
44 \\
(12)\end{array}$ & $\begin{array}{r}43 \\
45 \\
(13)\end{array}$ \\
\hline Household Head With 2 or More Years of College & $\%$ & 45.3 & 47.6 & 405 \\
\hline Two Wage Earner Family & $\%$ & 50.1 & 50.1 & 512 \\
\hline
\end{tabular}


Table 1 (Continued)

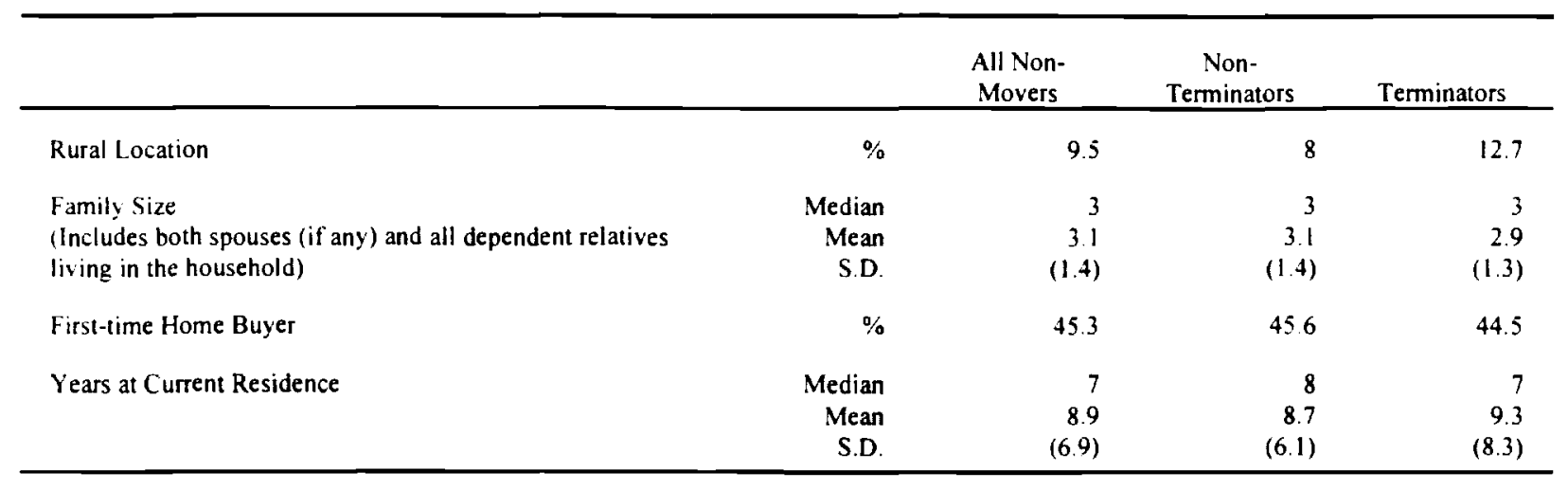


"Source is authors' tabulations and estimates from the American Housing Survey, 1985 and 1987 National Files supplemented with non-housing expense estimates from the Internal Revenue Service 1985 Individual Tax Model File. Reported values are either raw percentages or sample medians and means with standard deviations in parentheses.

${ }^{b}$ If the ratio of the market value of the primary mortgage to the book value of the primary mortgage is greater than one, then the option is 'in the money'.

'If the annual payment-to-income ratio (as if current balance of first mortgage debt is refinanced as a fixed-rate thirty year mortgage at market rate) is greater than .28 then the household is liquidity constrained.

${ }^{d}$ If the book loan-to-value ratio is greater than or equal to .9 then the household is collateral constrained.

'Market value of first mortgage is the present value of the remaining payments discounted over the remaining loan period using Freddie Mac's monthly commitment rate on 30 year fixed-rate mortgages (the lowest rate for the period of the AHS survey is used).

${ }^{f}$ Potential 'wasted' interest as a percentage of house value is used as a proxy for the mean weighted-average tax rate at which mortgage interest is deducted. Potential wasted interest represents the maximum amount of mortgage interest that will produce no tax savings due to the difference between the household's standard deduction and other itemized personal deductions, including property taxes. The potential wasted interest dollar amount is scaled by the fair market value of the residence and its sign is reversed because higher wasted interest represents a lower weighted average tax rate. 
Table 2

Logistic Regressions Explaining Termination of Primary Mortgage."

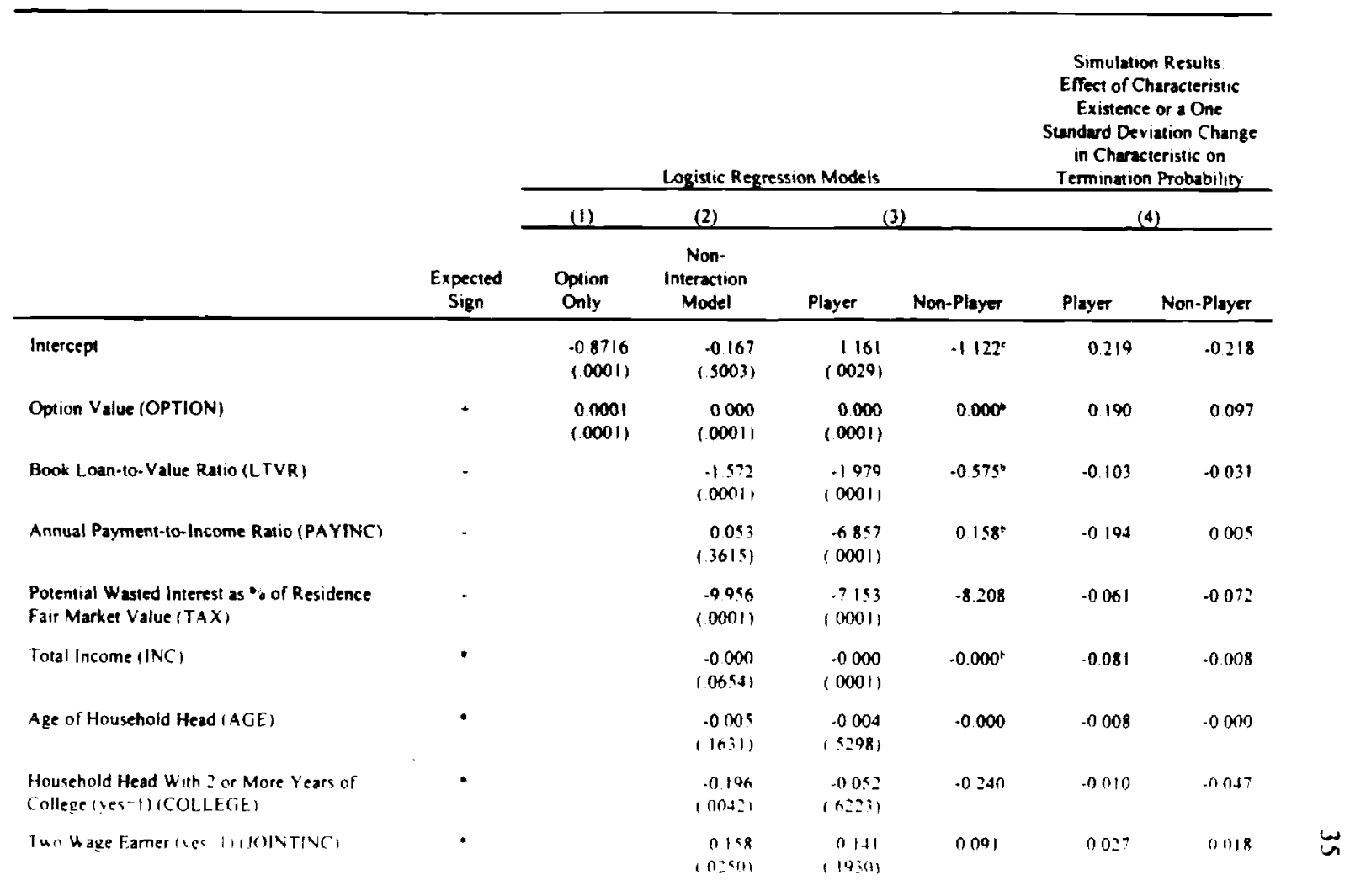




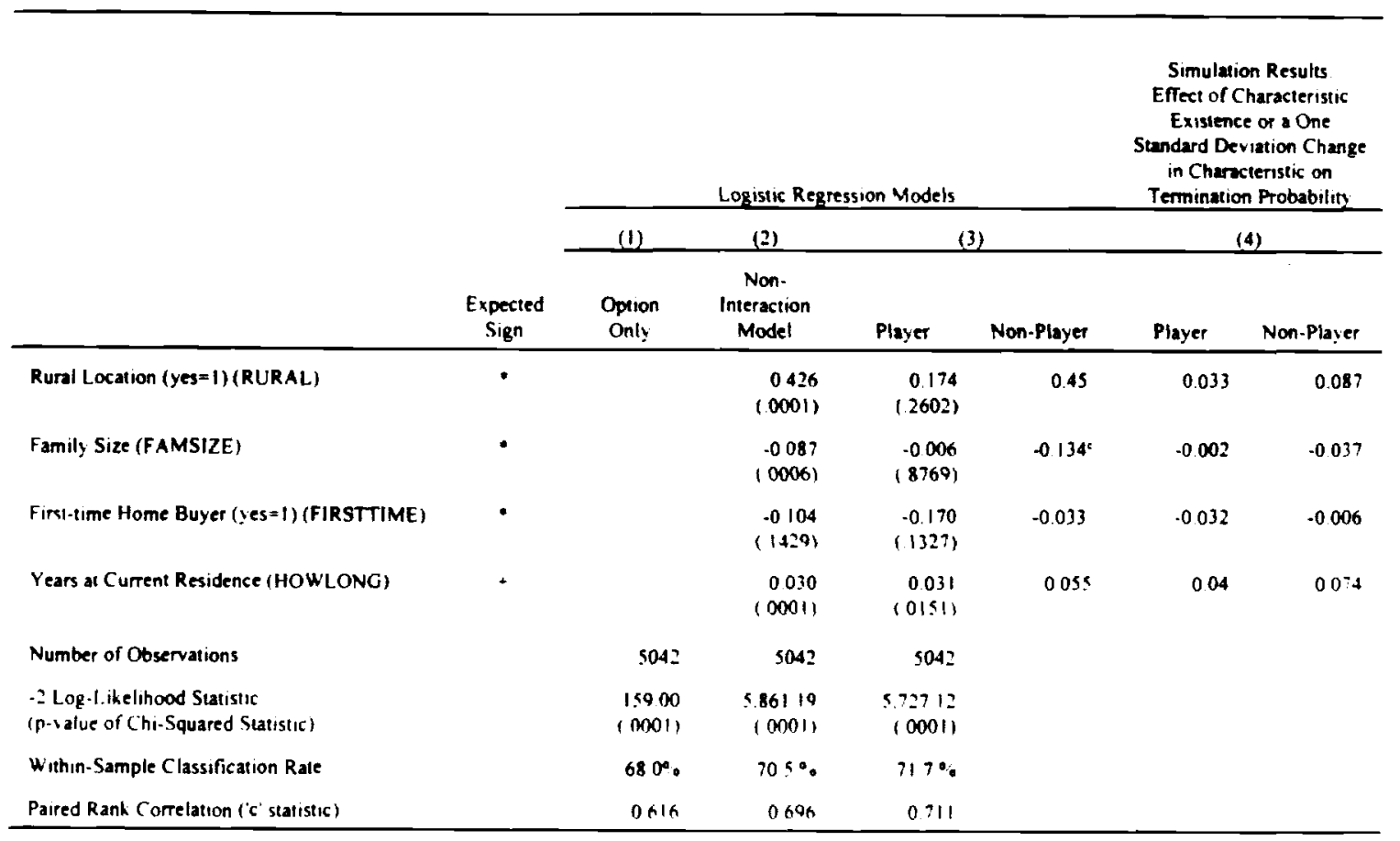


- Reported values are parameter estimates with p-values of Wald Chi-Square statistics in parentheses. Model (1) is estimated using the full sample and only OPTION as an explanatory variable. Model (2) is estimated using the full sample and no interaction effects. Model (3) is estimated as a fully interactive model with a dummy variable for PLAYER in order to examine the incremental intercept and slope effects of the household being a PLAYER. For this model, the second column contains the lotal parameter estimate when the household is not a 'player'. Where these parameter estimates statistically differ from the 'player' household estimates, the significance level is noted as: ${ }^{b}<.001 .^{c}<.05,{ }^{d}<.10$. Model (4) contains the results of a simulation to determine the effect on probability of termination of either the existence of a characteristic (in the case of dummy variables) or a one standard deviation increase in a characteristic (for continuous variables). Since household characteristics proxy for multiple effects. the expected sign for the specific explanatory variables are indeterminate and noted with a 
Table 3

Probabilities of Termination: Simulation of Alternative Scenarios for PLAYERs."

\begin{tabular}{lrr}
\hline & $\begin{array}{c}\text { Marginal } \\
\text { Constraint }\end{array}$ & $\begin{array}{c}\text { Deep } \\
\text { Constraint }^{\mathrm{c}}\end{array}$ \\
\hline Panel A: Prepayment Option In-the-Money & \\
No Constraints Binding & 0.386 & 0.386 \\
Collateral Constraint Binding & 0.236 & 0.170 \\
Payment Constraint Binding & 0.175 & 0.003 \\
Both Constraints Binding & 0.095 & 0.000 \\
Panel B: Prepayment Option At-the-Money & & \\
No Constraints Binding & 0.197 & 0.197 \\
Collateral Constraint Binding & 0.108 & 0.074 \\
Payment Constraint Binding & 0.077 & 0.001 \\
Both Constraints Binding & 0.039 & 0.000 \\
Panel C: Prepayment Option Deep Out-of-the-Money & \\
No Constraints Binding & 0.166 & 0.166 \\
Collateral Constraint Binding & 0.089 & 0.061 \\
Payment Constraint Binding & 0.063 & 0.001 \\
Both Constraints Binding & 0.000 & 0.000 \\
\hline
\end{tabular}


- Table values are predicted mortgage termination probabilities using the PLAYER coefficients from the logistic regression, evaluated at mean values for the PLAYER subset of sample except where constrained imposed (as noted).

b 'Marginal' constraints are achieved by setting each constraint variable at the maximum allowed for PLAYER: LTVR $=0.90$ and/or PAYINC $=0.28$.

c 'Deep' constraints are achieved by setting each constraint variable at its mean value for households in sample considered bound by the constraint: LTVR = $1.0163 \mathrm{and} /$ or $\mathrm{PAY} I N C=0.922$.

d For "In-the-money," the value of OPTION is set at the mean value for PLAYERs $(\$ 6,819.27)$; for "At-the-money," the value of OPTION is set at zero; for "Deep out-of-the-money," the value of OPTION is set at the mean of Non-PLAYERS (\$ $-1,500.00)$ 